\title{
LAMELLAR KERATOPLASTY FOLLOWED BY CATARACT EXTRACTION IN MALIGNANT PAPILLOMA OF THE LIMBUS*
}

BY

\author{
P. SIVASUBRAMANIAM and T. HOOLE \\ Eye Clinic, Civil Hospital, Jaffna, Ceylon
}

THE treatment of epibulbar growths depends on several factors of which the extent of involvement of the globe itself is the most important; to some extent the line of treatment adopted depends not only on the preference of a particular surgeon but also on the facilities available. Lamellar keratoplasty has often been employed as a therapeutic measure and we have had some experience of it (Sivasubramaniam and Hoole, 1952). The idea of keratoplasty in new growths of the cornea is not new, for Lister (1951) has reported a case of corneo-scleral grafting in malignant melanoma invading the cornea. The following case illustrates the surgical and technical principles involved in the line of treatment adopted.

\section{Case Report}

A 48-year-old woman complained of loss of sight of one year's duration.

Examination.-On January, 7, 1953, each eye had a mature senile cataract. Vision in each was hand movements. The right eye showed in addition a greyish-white, horse-shoe shaped plaque-like growth, situated at the upper limbus and spreading on to the upper two-fifths of the cornea but sparing the pupillary area (Fig. 1). The growth, which was friable and bled easily on manipulation, was raised $0 \cdot 5-1 \mathrm{~mm}$. above the corneal surface and did not involve the deeper layers of the cornea. Neither the parotid nor the cervical

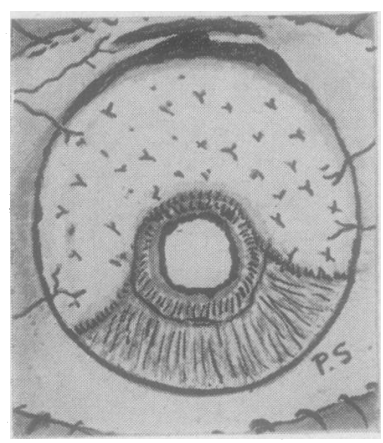

FIG. 1.-Growth riddled with blood vessels, clear cornea opposite pupil, and mature senile cataract.

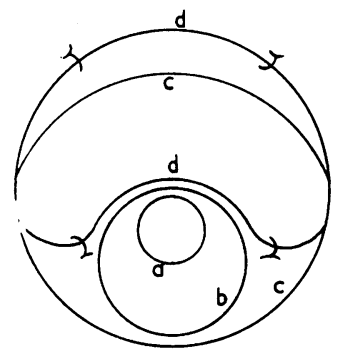

Fig. 2.-Diagram to illustrate operations: (a)pupillary border; (b) trephine mark; (c) limbus of host cornea; (d) outlines of growth and graft. lymph nodes were enlarged.

\section{Operations}

(a) Lamellar keratoplasty was done on January 14, 1953, under topical anaesthesia supplemented by retro-ocular novocaine. A freehand incision was made into the superficial layers of the cornea about 0.5 $\mathrm{mm}$. away from the edge of the growth. The plaque was removed entire by performing a superficial keratectomy together with excision of the conjunctiva and episclera in the upper limbus. Bleeding was arrested by the application 
of hot probes. Next, while planning to cut the graft out of the donor eye it occurred to one of us (T.H.) that a 6-mm. keratoplasty trephine would fit into the " horns" of the horse-shoe shaped area (Fig. 2). The idea of cutting the graft by making measurements and freehand incision was, therefore, abandoned. A 6-mm. trephine with the scale set at $0.5 \mathrm{~mm}$. was placed with its edge flush with the limbus and a cut made. A freehand incision was made along the rest of the limbus (Fig. 2). A Bock's lamellar keratoplasty knife was used to cut the lamella of cornea from the donor eye, starting from the limbus away from the trephine mark. The horse-shoe shaped lamella of cornea thus removed was transferred to the recipient bed and anchored by four sutures, two corneal and two corneo-conjunctival. Penicillin drops were instilled and the eye bandaged. Healing was uninterrupted. On the seventh day the sutures were removed and thereafter cortisone drops 0.5 per cent. were instilled to prevent neovascularization. The graft remained clear except at the upper limbus where a certain amount of haze was noticeable.

(b) Cataract extraction was performed on February 11, 1953; the right lens was extracted extracapsularly, and on March 13, 1953, the posterior capsule was needled.

Results.-When the patient left hospital on April 1, 1953, her vision was 6/36 with +10 D. sph. +2 D. cyl., ax $180^{\circ}$.

Pathologist's Report.-The section is that of a malignant papilloma of the limbus.

\section{Comment}

The treatment of malignant papilloma of the limbus by excision is a feasible proposition owing to its low malignancy and superficiality. To leave a large area of cornea denuded after excision is not desirable and a corneal graft is obviously the best means of covering the area.

\section{Difficulties in Operative Technique}

The cutting of a large lamellar graft which is not circular presents great difficulties, the chief of which is the maintenance of uniformity in the thickness of the lamella. The matching of the shape of the graft to the recipient bed is an exercise in keratoplasty. The horns of the graft were missing to some extent. When the graft was reposed on its bed the former overlapped the upper limbus by $1 \mathrm{~mm}$. Fortunately, though not by design, this fitted into a defect in the conjunctiva and episclera which was excised together with the growth. It would not have mattered if the graft had lain flush with the upper limbus as the conjunctiva could have been approximated by undermining. Direct suturing appeared to be the best method of fixing the graft. Small irregularities and defects in the edges of the graft, especially in the region of the "horns" epithelialized satisfactorily. Though the concave border of the graft was thicker, it united with the host border at the end of 3 weeks without leaving much evidence of a hump.

The next point of interest is the placing of the cataract section at the upper limbus. The knife was drawn out at the limbus, but during its traverse itcut the lamella of cornea that overlapped the sclera; the "feel " was different from usual because the knife encountered a little rigid corneal tissue instead of the soft conjunctiva. Though the wound did not gape easily and its lips were thick, extraction of the lens presented no difficulty, nor was there any delay in the healing of the wound. 
Visual Result.-As is evident from the description and diagrams, this did not depend on the clarity of the graft; had the graft turned opaque the visual result would have been little affected, for the host cornea was clear opposite the pupil. The reason for the vision being in the order of $6 / 36$ is to be found in the astigmatism induced by the grafting and the cataract extraction.

In this case the surgeon's preference and the available facilities prompted a certain line of treatment. Having no $x$-ray apparatus at our disposal we decided to excise the growth; and, having decided on this, we were happy indeed when a donor cornea was made available to us a few hours before operation.

We thank Dr. G. H. Cooray, Reader in Pathology, University of Ceylon, for reporting on the biopsy specimen, and Dr. C. M. Vanniasegeram, Medical Officer-in-Charge of the Jaffina Civil Hospital, for permission to publish this report.

\section{REFERENCES}

LisTeR, A. (1951). Trans. ophthal. soc. U.K., 71, 97.

Sivasubramaniam, P., and Hoole, T. (1952). Ceylon. med. J., $1,150$. 